\title{
PENGARUH DAYA TARIK, KEPERCAYAAN, DAN KEAHLIAN CELEBRITY ENDORSER TERHADAP KEPUTUSAN PEMBELIAN
}

\author{
Berlintina Permatasari1) \\ 1) Manajemen, Universitas Teknokrat Indonesia \\ Jl. H.ZA Pagaralam, No 9-11, Labuhanratu,Bandarlampung \\ Email : berlintina.teknokrat.ac.id ${ }^{1}$ )
}

\begin{abstract}
ABSTRAK
Berbagai taktik pemasaran dilakukan agar produk semakin kompetitif dan menjadi pilihan konsumen. Salah satu usaha yang dilakukan adalah dengan menggunakan selebriti pendukung. Tujuan dari penelitian ini adalah untuk menguji pengaruh daya tarik, kepercayaan, dan keahlian Valentino Rossi sebagai celebrity endorser terhadap keputusan pembelian motor Yamaha R Series di Bandar Lampung. Teknik pengambilan sampel yang digunakan dalam penelitian ini adalah Accidental Sampling, yaitu teknik penentuan sampel berdasarkan kebetulan, sedangkan untuk teknik analisis data dengan menggunakan regresi linier berganda. Hasil penelitian ini menunjukkan bahwa variabel daya tarik, kepercayaan, dan keahlian memiliki efek yang signifikan dan positif dalam keputusan pembelian.
\end{abstract}

Kata Kunci: keputusan pembelian, celebrity endorser, daya tarik, kepercayaan, keahlian.

\section{PENDAHULUAN}

\section{Latar belakang}

Keputusan pembelian merupakan preferensi konsumen yang dibentuk melalui keterlibatan konsumen dalam proses pencarian informasi, semakin tinggi konsumen terlibat, maka akan semakin besar dorongan konsumen untuk melakukan pembelian. Salah satu cara agar informasi dapat menyebar secara massif dan luas adalah melalui iklan. Iklan merupakan alat komunikasi pemasaran yang kuat, karena dengan cepat dapat menyebar luas pada masyarakat dan bersifat persuasif (Apejoye, 2013). Menurut Kotler dan Keller (2009), periklanan merupakan salah satu media yang digunakan perusahaan, dapat diklasifikasikan menurut tujuannya, yaitu untuk memberikan informasi, membujuk, dan mengingat. Perusahaan harus memiliki cara kreatif dalam mengiklankan produknya agar dapat menarik perhatian konsumen, salah satu caranya adalah dengan menggunakan model dalam iklan, hal ini dikenal dengan istilah endorser.

Celebrity endorser yang dapat mempengaruhi perilaku konsumen merupakan aset yang berharga bagi pihak pemasar. Celebrity endorser dapat memberikan testimoni mengenai manfaat produk, mendukung sebuah produk, dan bertindak sebagai juru bicara untuk produk yang diiklankan (Blackwell dkk, 2006). Selain itu, penampilannya di dalam iklan secara halus dapat mempengaruhi konsumen, serta dapat mengasosiasikan merek yang diiklankan dengan kepribadian mereka (Hollensen dan Schimmelpfenning, 2013). Untuk mempercayai klaim yang dibuat oleh suatu merek dan mempengaruhi perilaku konsumen, celebrity endorser harus memiliki kredibilitas, antara lain pengetahuan yang relevan, keterampilan atau pengalaman yang dianggap berbobot (Ohanian, 1990).

Salah satu industri yang sangat berkembang saat ini adalah industri otomotif, khususnya sepeda motor. Industri ini telah melahirkan berbagai merek besar diantaranya Honda, Yamaha, Suzuki, Kawasaki, dan merek-merek lainnya. Masalah yang dihadapi oleh industri sepeda motor adalah persaingan antar perusahaan yang semakin kompetitif dalam memasarkan produknya. Berbagai taktik pemasaran dilakukan oleh para produsen, agar produknya menjadi pilihan konsumen. Salah satu usaha yang dilakukan oleh Yamaha, sebagai salah satu produsen sepeda motor saat ini adalah dengan menggunakan celebrity endorser guna membangun brand awareness bagi produk motor sport barunya, Yamaha R Series. Yamaha menggunakan Valentino Rossi sebagai pembalap kelas dunia untuk mengendorse produk barunya.

Celebrity endorser merupakan orang yang diakui atau dikenal secara luas oleh publik dan dengan pengakuan tersebut, perusahaan menggunakannya untuk mengiklankan produknya (McCracken, 1989). Menurut Ifeanyichukwu (2016), konsumen mengakui peran dan kekuatan selebritas dalam periklanan, peran selebriti pendukung jika dikelola dengan tepat maka akan sangat membantu dalam memposisikan merek dalam benak konsumen. Menggunakan selebriti pendukung yang tepat, sangat penting untuk keberhasilan iklan dalam era dewasa ini, karena konsumen hidup dalam lingkungan yang terpapar penuh oleh media. Selebriti mampu menarik lebih banyak perhatian konsumen pada iklan yang muncul, ketika produk yang mereka dukung diselaraskan dengan citra selebriti sendiri (McCormick, 2016). Kredibilitas celebrity endorser adalah karakter positif seorang pemberi pesan yang dapat mempengaruhi penerimaan penerima dari pesan tersebut (Ohanian, 1990). Lebih lanjut Ohanian (1990), mengelompokkan kredibilitas celebrity endorser ke dalam 3 (tiga) dimensi yaitu, daya tarik (attractiveness), kepercayaan (trustworthiness), dan keahlian (expertise).

\section{Masalah}

Rumusan permasalahan dalam penelitian ini adalah, apakah daya tarik, kepercayaan dan keahlian celebrity 
endorser berpengaruh terhadap keputusan pembelian Yamaha R Series?

\section{Tujuan}

Penelitian ini diperlukan untuk menguji pengaruh daya tarik, kepercayaan dan keahlian celebrity endorser terhadap keputusan pembelian.

\section{PEMBAHASAN}

\section{Uji Validitas}

Validitas adalah kesesuaian hasil-hasil simpulan sebuah penelitian dengan kondisi nyata di lapangan, dengan begitu suatu hasil penelitian dikatakan valid jika hasil tersebut memiliki tingkat kesesuaian yang tinggi dengan kondisi riil. Pengujian validitas ditujukan untuk melihat hubungan antar masing-masing butir pertanyaan pada variabel bebas dan variabel terikat. Analisis faktor akan menampilkan hasil ekstaksi butir-butir pertanyaan menjadi beberapa komponen yang diinginkan.

Berdasarkan output uji validitas yang diperoleh seluruh butir pertanyaan telah memenuhi syarat uji validitas yang dimana nilai skor total Pearson Correlation masing-masing instrumen berada diatas 0,30. Hal ini membuktikan bahwa seluruh butir pertanyaan, dalam hal ini dianggap valid.

Tabel 1. Hasil Uji Validitas

\begin{tabular}{|llccc|}
\hline No & Variabel & Instrumen & $\begin{array}{c}\text { Pearson } \\
\text { Correlation }\end{array}$ & Ket \\
\hline 1. & Daya Tarik & X1.1 & 0,688 & Valid \\
& (X1) & X1.2 & 0,715 & Valid \\
& & X1.3 & 0,388 & Valid \\
& & X1.4 & 0,430 & Valid \\
& & X1.5 & 0,430 & Valid \\
2. & Kepercayaan & X2.1 & 0,783 & Valid \\
& (X2) & X2.2 & 0,757 & Valid \\
& & X2.3 & 0,647 & Valid \\
& & X2.4 & 0,437 & Valid \\
& & X2.5 & 0,412 & Valid \\
3. Keahlian & X3.1 & 0,806 & Valid \\
& (X3) & X3.2 & 0,760 & Valid \\
& & X3.3 & 0,664 & Valid \\
& & X3.4 & 0,409 & Valid \\
& & X3.5 & 0,393 & Valid \\
& & & & \\
4. & Keputusan & Y1 & 0,817 & Valid \\
& Pembelian & Y2 & 0,682 & Valid \\
& (Y) & Y3 & 0,754 & Valid \\
& & Y4 & 0,608 & Valid \\
& & Y5 & 0,395 & Valid \\
\hline
\end{tabular}

Sumber: Data diolah, 2019

Berdasarkan hasil perhitungan uji validitas seluruh butir pertanyaan dari masing-masing variabel dianggap valid.

\section{Uji Reliabilitas}

Menurut Sugiyono (2006), reliabilitas adalah indeks yang menunjukkan sejauh mana suatu alat ukur dapat dipercaya atau diandalkan. Uji reliabilitas dilakukan untuk mengetahui konsistensi dan ketepatan pengukuran, apabila pengukuran dilakukan pada objek yang sama berulang kali dengan instrumen yang sama. Pengujian reliabilitas adalah suatu pengujian pada instrumen penelitian demi mendapatkan hasil bahwa instrumen yang digunakan dapat dipercaya dan diandalkan. Pengujian ini, nilai suatu reliabilitas ditunjukkan melalui skor Cronbach's Alpha yang dimana jika nilai skor tersebut berada diatas 0,60 maka instrumen tersebut dapat dikatakan reliabel. Hasil penelitian uji reliabilitas dapat dilihat pada Tabel 2.

Tabel 2. Hasil Uji Reliabilitas

\begin{tabular}{|llll|}
\hline Variabel & $\begin{array}{l}\text { r } \\
(\text { Cronbach } \\
\text { Alpha })\end{array}$ & r-min & Ket \\
\hline Daya Tarik $\left(\mathrm{X}_{1}\right)$ & 0,804 & 0,6 & Reliabel \\
Kepercayaan $\left(\mathrm{X}_{2}\right)$ & 0,782 & 0,6 & Reliabel \\
Keahlian $\left(\mathrm{X}_{3}\right)$ & 0,736 & 0,6 & Reliabel \\
Keputusan & 0,775 & 0,6 & Reliabel \\
Pembelian (Y) & & & \\
\hline
\end{tabular}

Sumber: Data diolah, 2019

\section{Analisis Regresi Linier Berganda}

Analisis regresi linier berganda meliputi berbagai perhitungan dan pengujian, yaitu penentuan persamaan regresi, perhitungan koefisien determinasi, dan pengujian signifikansi variabel independen. Analisis data secara kuantitatif dilakukan melalui pendekatan statistik, yaitu dengan model analisis regresi linear berganda yang digunakan untuk mengetahui besarnya pengaruh variabel bebas, antara lain Daya Tarik $\left(\mathrm{X}_{1}\right)$, Kepercayaan $\left(\mathrm{X}_{2}\right)$, dan Keahlian $\left(\mathrm{X}_{3}\right)$, terhadap variabel terikat, yaitu Keputusan Pembelian (Y). Berdasarkan hasil perhitungan dengan software SPSS 25.0, diperoleh hasil sebagai berikut.

Tabel 3. Hasil Uji Simultan F

\begin{tabular}{|llrrl|}
\hline & Model & Mean Square & F & Sig. \\
\hline 1 & Regression & 117.589 & 25.149 & $.000^{\mathrm{b}}$ \\
& Residual & 4.676 & & \\
& Total & & & \\
\hline
\end{tabular}

a. Dependent Variable: KeputusanPembelian

b. Predictors: (Constant), Keahlian, DayaTarik,

Kepercayaan

Sumber: Data diolah, 2019

Dari tabel uji simultan (F) menunjukan bahwa daya tarik, kepercayaan, dan keahlian celebrity endorser secara simultan berpengaruh signifikan terhadap keputusan pembelian dengan nilai Fhitung sebesar 25.149 , dengan nilai probabilitas $<0,05$, yaitu $(0,000<$ $0,05)$, maka model regresi dapat digunakan untuk memprediksi variabel Keputusan Pembelian (Y) atau dengan kata lain variabel Daya Tarik (X1), Kepercayaan (X2), dan Keahlian (X3) secara bersama- 
sama berpengaruh nyata terhadap variabel Keputusan Pembelian (Y).

\section{Pengujian Hipotesis}

Pengujian signifikan nilai t hitung dilakukan dengan menggunakan angka signifikansi atau Sig. pada kolom tabel coefficient dengan ketentuan sebagai berikut:

1. Jika angka signifikansi penelitian $<0,05$, maka $\mathrm{H}_{0}$ ditolak dan $\mathrm{H}_{\mathrm{a}}$ diterima, yang berarti variabel yang diuji signifikan.

2. Jika angka signifikansi penelitian $>0,05$, maka $\mathrm{H}_{0}$ diterima dan $\mathrm{H}_{\mathrm{a}}$ ditolak, yang berarti variabel yang diuji signifikan.

Tabel 4. Nilai Sig. dan $t_{\text {hitung }}$ Untuk Masing-masing Variabel Bebas

\begin{tabular}{|lcc|}
\hline \multicolumn{1}{|c|}{ Variabel Bebas } & thitung & Sig. \\
\hline Daya Tarik $\left(\mathrm{X}_{1}\right)$ & 2,259 & 0,026 \\
Kepercayaan $\left(\mathrm{X}_{2}\right)$ & 3,054 & 0,003 \\
Keahlian $\left(\mathrm{X}_{3}\right)$ & 2,410 & 0,018 \\
\hline
\end{tabular}

Sumber: Data diolah, 2019

\section{Penjelasan data dari Tabel 4 sebagai berikut:}

\section{a. Pengujian Koefisien Parsial Variabel Daya Tarik} $\left(\mathbf{X}_{1}\right)$.

Nilai $t_{\text {hitung }}(2,259)$ dan nilai signifikan $0,026<0,05$, maka $\mathrm{H}_{0}$ ditolak dan $\mathrm{H}_{\mathrm{a}}$ diterima pada tingkat kepercayaan 95\%. Artinya secara parsial ada pengaruh antara Daya Tarik $\left(\mathrm{X}_{1}\right)$ terhadap Keputusan Pembelian (Y). Hal ini dapat dinyatakan secara statistik bahwa semakin positif daya tarik celebrity endorser dalam iklan motor Yamaha R Series, maka akan semakin tinggi pula keputusan pembelian konsumen terhadap produk motor tersebut. Iklan dapat dikatakan menarik apabila menampilkan ide-ide kreatif dan berbeda dari iklan lainnya. Menurut Shimp (2003), iklan yang sama dengan sebagian iklan lainnya tidak akan mampu menerobos kerumunan iklan kompetitif dan tidak akan dapat menarik perhatian konsumen. Selebriti memiliki daya tarik dalam berbagai cara untuk menarik khalayak sasaran guna melakukan keputusan pembelian (Shimp, 2003).

Daya tarik tidak hanya dilihat dari aspek fisik, akan tetapi harus meliputi sejumlah karakteristik yang dapat dilihat khalayak dalam diri celebrity endorser, antara lain; kecerdasan, sifat-sifat kepribadian, serta gaya hidup. Beberapa studi penelitian telah menyimpulkan bahwa daya tarik fisik memiliki pengaruh. selebriti pendukung yang memiliki daya tarik, akan mampu dan mempengaruhi konsumen, bahkan di lingkungan media yang berantakan (Chen dan Huddleston, 2009). Akibatnya, persepsi konsumen terhadap citra merek meningkat. Selain itu, daya tarik selebriti juga dapat meningkatkan daya ingat merek dan sikap positif terhadap merek (Kahle dan Homer, 1985). Meskipun daya tarik selebriti pendukung tidak selalu menghasilkan perubahan langsung dalam sikap, berbagai penelitian telah mengkonfirmasi bahwa hal tersebut merupakan proses awal yang penting dari pengaruh sosial (Byrne et al, 2003). Singkatnya, seseorang akan mengevaluasi pesan dukungan secara positif jika dia memiliki sikap positif terhadap selebriti pendukung. Hal tersebut diperkuat dengan penelitian Liu et al, (2007). bahwa konsumen biasanya mensyaratkan bahwa selebriti pendukung harus memiliki penampilan yang menarik. Daya tarik selebriti juga dapat digunakan sebagai variabel untuk meningkatkan pengakuan atau kesadaran akan suatu produk atau layanan (Liu et al, 2007; Ranjbarian et al, 2010). Daya tarik celebrity endorser sebagai komunikator merupakan hal yang penting. Penampilan fisik yang menarik dari selebriti menjadi salah satu bagian dari daya tarik. Konsumen akan cenderung membentuk kesan positif dan lebih percaya kepada apa yang disampaikan oleh selebriti dengan penampilan fisik yang menarik. Dengan menggunakan celebrity endorser sebagai bintang iklan suatu produk, maka daya tarik yang dimiliki oleh selebriti tersebut menjadi dimensi penting terhadap image produk yang diwakili, sehingga dapat mempengaruhi keputusan pembelian konsumen. Oleh karena itu, celebrity endorser yang menarik secara fisik, seperti Valentino Rossi, dapat menjadi personifikasi yang efektif untuk memengaruhi keputusan pembelian.

\section{b. Pengujian Koefisien Parsial Variabel Kepercayaan $\left(\mathbf{X}_{2}\right)$.}

Nilai thitung $(3,054)$ dan nilai signifikan $0,003<0,05$, maka $\mathrm{H}_{0}$ ditolak dan $\mathrm{H}_{\mathrm{a}}$ diterima pada tingkat kepercayaan $95 \%$. Artinya secara parsial ada pengaruh antara Kepercayaan $\left(\mathrm{X}_{2}\right)$ terhadap Keputusan Pembelian (Y). Hal ini dapat dinyatakan secara statistik bahwa semakin positif kepercayaan celebrity endorser (Valentino Rossi) dalam iklan motor Yamaha R Series, maka akan semakin tinggi pula keputusan pembelian konsumen terhadap produk motor tersebut. Hasil pengujian ini sangat sesuai dengan persepsi konsumen yang rata-rata mengatakan setuju atas kepercayaan celebrity endorser yang berpengaruh terhadap keputusan pembelian. Selebriti tertentu membangkitkan perasaan kepercayaan di antara konsumen, sehingga menciptakan niat perilaku positif (Erdogan, 1999). Oleh karena itu, kepercayaan terhadap selebriti pendukung dapat menjadi konstruksi penting bagi pengiklan. Atkin dan Block (1983) juga menemukan bahwa selebriti dipandang lebih dapat dipercaya dalam menyampaikan pesan dibandingkan dengan non-selebriti di seluruh kelompok umur.

Selebriti dianggap mewakili gaya hidup yang ideal, dimana sebagian orang atau paling tidak penggemar ingin mengikuti gaya hidupnya. Dengan adanya perilaku pasar yang ingin meniru gaya hidup selebriti, perusahaan rela mengeluarkan sejumlah uang yang tidak sedikit untuk bekerjasama dengan selebriti dalam mempromosikan produk atau merek mereka. Kredibilitas mengacu pada sejauh mana celebrity endorser diakui memiliki pengetahuan yang signifikan 
atau pengalaman yang cukup untuk menawarkan penilaian yang tidak memihak (Carroll, 2008. Jika informasi berasal dari sumber yang terpercaya, sikap, nilai, pendapat, dan perilaku konsumen dapat dipengaruhi melalui 'internalisasi' (Ohanian, 1991). Internalisasi terjadi ketika konsumen mengizinkan sumber (celebrity endorser dengan kredibilitas) untuk mempengaruhi sikap dan nilai pribadi mereka. Sebagaimana dinyatakan oleh Daneshvary dan Schwer (2000), seorang individu menerima pengaruh sumber (celebrity endorser) tidak hanya karena ia menawarkan solusi untuk suatu masalah tetapi juga karena kredibilitasnya.

Oleh karena itu, pengesahan produk oleh sumber yang kredibel dapat memengaruhi niat perilaku konsumen. Pengesahan dari sumber yang kredibel efektif bila digunakan pada konsumen yang memiliki persepsi negatif terhadap produk (Daneshvary dan Schwer, 2000). Untuk alasan itu, sumber yang dapat dipercaya dapat menetralkan persepsi ini dan menghasilkan penerimaan pesan yang lebih besar (Bryne et al, 2003). Namun, pemasar harus memperhatikan bahwa selebriti yang mendukung banyak produk dianggap kurang kredibel dibandingkan mereka yang mendukung produk tertentu (Silvera dan Austad, 2004). Secara umum, dua faktor penting menggarisbawahi konsep kredibilitas sumber: kepercayaan dan keahlian sumber (Chen dan Huddleston, 2009). Menurut Toncar et al (2007), kepercayaan dan keahlian sumber berkontribusi secara independen terhadap efektivitas sumber. Kepercayaan dapat didefinisikan sebagai kesediaan selebriti untuk membuat pernyataan yang sah (McCracken, 1989, dalam Ohanian, 1991). Erdogan (1999) mendefinisikan kepercayaan sebagai persepsi konsumen terhadap kejujuran, integritas dan kepercayaan seorang pendukung. Seperti yang ditunjukkan oleh O`Mahony dan Meenaghan (1997), kepercayaan sumber adalah atribut nyata yang mendasari kredibilitas sumber yang mempengaruhi perubahan sikap pada konsumen. Tanpa kepercayaan, atribut lain yang dimiliki oleh endorser tidak akan efektif dalam mengubah sikap konsumen (Miller dan Basehart, 1969).

Menurut Wang dan Scheinbaum (2018), pengiklan yang ingin meningkatkan kredibilitas merek mereka harus berinvestasi pada selebriti pendukung yang dianggap konsumen sebagai orang yang dapat dipercaya. Pengiklan yang menggunakan selebriti pendukung harus mampu menampilkan selebriti yang dapat dipercaya untuk mempengaruhi basis konsumen dan meningkatkan keterlibatan mereka.

\section{c. Pengujian Koefisien Parsial Variabel Keahlian $\left(\mathbf{X}_{3}\right)$.}

Nilai thitung $(2,410)$ dan nilai signifikan $0,018<0,05$, maka $\mathrm{H}_{0}$ ditolak dan $\mathrm{H}_{\mathrm{a}}$ diterima pada tingkat kepercayaan $95 \%$. Artinya secara parsial ada pengaruh antara Keahlian $\left(\mathrm{X}_{3}\right)$ terhadap Keputusan Pembelian (Y). Hal ini dapat dinyatakan secara statistik bahwa semakin positif keahlian celebrity endorser (Valentino Rossi) dalam iklan motor Yamaha R Series, maka akan semakin tinggi pula keputusan pembelian konsumen terhadap produk motor tersebut. Hasil pengujian ini sangat sesuai dengan persepsi konsumen yang rata-rata mengatakan setuju atas keahlian celebrity endorser (Valentino Rossi) yang berpengaruh terhadap keputusan pembelian. Maddux dan Rogers (1980) dan Ohanian (1991), menyimpulkan bahwa seorang selebriti pendukung yang memiliki keahlian tinggi dapat menghasilkan persepsi dan sikap positif terhadap produk atau layanan.

Valentino Rossi dikenal karena reputasiya di dunia balap sepeda motor dan dengan demikian akan menjadi pendukung yang sangat baik untuk produk-produk terkait. Demikian pula, Dean dan Biswas (2001) menyatakan bahwa keahlian muncul sebagai konstruk yang paling efektif untuk persuasi dukungan dalam periklanan merek utilitarian dan mahal. Oleh karena itu lebih efektif untuk menggunakan seorang selebriti atau atlet dengan keahlian yang relevan sebagai pendukung daripada menggunakan pesan dan advertorial konvensional yang disampaikan oleh organisasi (Charbonneau dan Garland, 2005). Sehinga dapat disimpulkan bahwa penggunaan Valentino Rossi sebagai celebrity endorser sudah relevan, karena Valentino Rossi dapat dipersepsikan sebagai ahli dan memiliki relevansi dengan produk yang dia dukung.

Menurut Noviandra (2006), keahlian celebrity endorser dapat mengacu pada informasi yang disampaikan oleh sumber pesan dengan cara mempersepsikan produk yang diiklankan, hal ini untuk menunjang keterkaitan dengan produk atau merek yang diwakili. Keahlian adalah dimensi selanjutnya dari kredibilitas sumber (McCracken, 1989). Menurut Erdogan (1999), keahlian dalam kredibilitas celebrity endorser mengacu pada keterampilan, pengetahuan atau pengalaman yang dimiliki oleh seorang selebriti pendukung. Oleh karena itu, selebriti pendukung dianggap sebagai ahli di bidangnya masing-masing (Biswas et al, 2006). Silvera dan Austad (2004) menemukan bahwa keahlian endorser berkaitan dengan validitas klaim mengenai produk, dan dengan demikian ini dianggap sebagai faktor penting dalam meningkatkan persuasi pesan pemasaran. Lebih khusus lagi, keahlian seorang selebriti memberi konsumen informasi yang lebih konkret tentang penawaran produk, yang kemudian mengarah pada sikap yang menguntungkan terhadap merek (Magnini et al, 2008).

Lebih lanjut, penelitian tentang keahlian selebriti pendukung telah menyarankan bahwa keahlian yang dirasakan dari seorang selebriti pendukung dapat mengarahkan perubahan sikap positif pada produk (Erdogan, 1999). Akibatnya, perilaku konsumen dan niat beli dapat dihasilkan (Erdogan, 1999). Sebagaimana dinyatakan oleh Atkin dan Block (1983), menggunakan juru bicara ahli sebagai pendukung sangat penting untuk produk dan layanan yang memiliki risiko fisik, keuangan, atau kinerja yang lebih tinggi. Untuk produk dan layanan risiko rendah dan non-keuangan, testimoni 
konsumen dianggap cukup untuk menciptakan respons perilaku yang menguntungkan.

\section{KESIMPULAN}

Berdasarkan hasil analisis dapat diketahui bahwa faktor yang paling dominan mempengaruhi keputusan pembelian oleh konsumen adalah kepercayaan kepada celebrity endorser. Konsumen memandang selebriti yang dapat memberikan inspirasi, memiliki prestasi dan pengetahuan yang cukup tentang produk yang diiklankannya, serta sukses dalam karir dapat mempengaruhi keputusan pembelian mereka.

Faktor kedua yang memiliki pengaruh yang cukup besar terhadap keputusan pembelian adalah keahlian celebrity endorser. Berdasarkan hasil analisis dapat diketahui selebriti mampu menjadi pengiklan yang baik dengan keahlian yang dimilikinya, seperti cara berkomunikasi yang efektif, penggunaan bahasa yang tepat, dan memiliki pengalaman yang terkait dengan produk atau merek, serta adanya keterampilan yang berhubungan dengan topik iklan. Keahlian yang dimiliki oleh Valentino Rossi sebagai pembalap kelas dunia sangat identik dengan segmentasi pasar Yamaha R Series.

Faktor ketiga yang berpengaruh terhadap keputusan pembelian adalah daya tarik celebrity endorser. Hasil analisis menyatakan bahwa skala usia responden 17-25 tahun, maka penggunaan Valentino Rossi sebagai celebrity endorser pada iklan motor Yamaha R Series cukup tepat untuk menjadi daya tarik bagi konsumen yang tergolong anak muda hingga dewasa.

\section{DAFTAR PUSTAKA}

[1] Apejoye A, "Influence of Celebrity Endorsement of Advertisement on Students' Purchase Intention", J Mass Communication Journalism 3: 152, 2013.

[2] Kotler, P. dan Keller, K, Manajemen Pemasaran Edisi 13 Jilid 1, Jakarta: Pearson Education, 2009.

[3] Blackwell, R.D., Miniard, P.W. and Engel, J.F, Consumer Behavior, 9th ed., South-Western Thomas Learning, Mason, OH, 2006.

[4] Hollensen, S. dan Schimmelpfennig, C, "Selection of Celebrity Endorsers", Marketing Intelligence \& Planning, Vol. 31 (1): 88 - 102, 2013.

[5] Ohanian, R, "Construction And Validation Of A Scale To Measure Celebrity Endorsers' Perceived Expertise, Trustworthiness And Attractiveness", Journal of Advertising, Vol. 19 No. 3: 39 - 52, 1990.

[6] McCracken, G, "Who Is the Celebrity Endorser? Cultural Foundations Of The Endorsement Process", Journal of Consumer Research, Vol. 16 No. 3: 310-321, 1989.
[7] Ifeanyichukwu, C, "Effect of Celebrity Endorsements on Consumers Purchase Decision in Nigeria”, International Research Journal of Management, IT \& Social Sciences, Vol. 3 No. 9: 120-128, 2016.

[8] McCormick, K, “Celebrity endorsements: Influence of a product-endorser match onMillennials attitudes and purchase intentions", Journal of Retailing and Consumer Services, Vol. 32: 39-45, 2016.

[9] Sugiyono, Metode Penelitian Bisnis, Bandung: CV. Alpha Betha, 2006.

[10] Shimp, T, Periklanan Promosi Jilid 1, Jakarta: Erlangga, 2003.

[11] Chen, S.M. \& Huddleston, P, "A Comparison of Four Strategies to Promote Fair Trade Products", International Journal of Retail and Distribution Management, 37(4), 336-345, 2009.

[12] Kahle, L.R. \& Homer, P, "Physical attractiveness of the celebrity endorser: a social adaptation perspective”. Journal of Consumer Research, 11(3), 954-61, 1985.

[13] Bryne, A., Whitehead, M. \& Breen, S, "The Naked Truth of Celebrity Endorsement", British Food Journal, 105(4/5), 288-296, 2003.

[14] Liu, M.T., Huang, Y.Y. \& Jiang, M.H, "Relations among Attractiveness of Endorsers, Match-up, and Purchase Intention in Sport Marketing in China". Journal of Consumer Marketing, 24(6), 358-365, 2007.

[15] Ranjbarian, B., Shekarchizade, Z. \& Momeni, Z, "Celebrity Endorser Influence On Attitude Toward Advertisement And Brands". European Journal of Social Science, 13(3), 399-404, 2010.

[16] Erdogan, B. Z, “Celebrity Endorsement: A Literature Review”. Journal of Marketing Management, 15(4), 291-314, 1999.

[17] Atkin, C. \& Block, M, "Effectiveness Of Celebrity Endorsers". Journal of Advertising Research, 23(1), 57-61, 1983.

[18] Carroll, A, Brand Communications in Fashion Categories Using Celebrity Endorsement, Brand Management, 17(2), 146-158, 2008.

[19] O'hanian, R, “The Impact Of Celebrity Spokespersons Perceived Image On Consumers Intention To Purchase”. Journal of Advertising Research, 31, 46-54, 1991.

[20] Daneshvary, R. \& Schwer, R. K, "The Association Endorsement and Consumers Intention to Purchase”. Journal of Consumer Marketing, 17(3), 203-213, 2000.

[21] Toncar, M., Reid, J.S. \& Anderson, C.E, "Effective Spokespersons In A Public Service Announcement: National Celebrities, Local Celebrities, And Victims". Journal of Communication Management, 11(3), 258-275, 2007. 
[22] OMahony, S. \& Meenaghan, T. (1997). “The Impact Of Celebrity Endorsements On Consumers". Irish Marketing Review, 10(2), pp.15-24, 1997.

[23] Miller, G.P. \& Basehart, J, "Source trustworthiness, opinionated statements, and response to persuasive communication". Speech Monographs, 36(1), 1-7, 1969.

[24] Wang, S.W. \& Scheinbaum, A, "Enhancing Brand Credibility via Celebrity Endorsement”. Journal Of Advertising Research, 2018.

[25] Maddux, J.E. \& Rogers, R.W. "Effects of Sources Expertness, Physical Attractiveness and Supporting Arguments on Persuasion: A Case of Brain over Beauty". Journal of Personality and Social Psychology, 39(2), 235244, 1980.

[26] Dean, D.H. \& Biswas, A, “Third-Party Oganization Endorsement of Products: An Advertising Cue Affecting Consumer Prepurchase Evaluation of Goods and Services". Journal of Advertising, 30(4), 41-57, 2001.

[27] Charbonneau, J. \& Garland, R, “Talent, Looks or Brains? New Zealand Advertising Practitioners Views on Celebrity and Athlete Endorsers". Marketing Bulletin, 16(3),1-10, 2005.

[28] Noviandra, M, “Analisis Pengaruh Model Iklan Terhadap Perilaku Pembelian Remaja Kasus Pada Bintang Akademi Fantasi Indosiar”, Jurnal Bisnis dan Ekonomi Universitas Diponegoro Vol. 10 No. 1: 30 - 36, 2006.

[29] Biswas, D., Biswas, A. \& Das, N, "The Differential Effects Of Celebrity And Expert Endorsements On Consumer Risk Perceptions". Journal of Advertising, 35(2), 17-31, 2006.

[30] Silvera, D.H. \& Austad, B, "Factors predicting the effectiveness of celebrity endorsement advertisements". European Journal of Marketing, 38(11/12), 1509-1526, 2004.

[31] Magnini, P.V., Honeycutt, E.D., \& Cross, A.M, "Understanding The Use Of Celebrity Endorsers For Hospitality Firms". Journal of Vacation Marketing, 14(1), 57-69, 2008. 